\title{
METHOD FOR ESTIMATING SERVICE LOAD FROM STRIATION WIDTH AND HEIGHT
}

\author{
Katsuaki FURUKAWA \\ Second Forensic Division, First Mechanical Section \\ National Research Institute of Police Science \\ 6-3-1 Kashiwanoha, Kashiwa-shi, Chiba 277-0882, Japan
}

\begin{abstract}
A case-study method is proposed to determine service loading from fracture surface striations. Although it is well known that striation spacing relates to the crack growth rate, it is considered impossible to determine maximum and minimum loads under service loading conditions, and to define the stress ratio $\mathrm{R}$ from an analysis of the striation spacing. This paper presents a new method of measuring the figure of striation using a laser microscope.
\end{abstract}

\section{KEYWORDS}

Fatigue fracture, striation configuration, laser microscope, three dimensional measurement, Stress ratio.

\section{INTRODUCTION}

More than $80 \%$ of machine structure fractures originate in fatigue. Consequently, to prevent recurrence, it is important to analyze the fracture surface in order to ascertain the cause of the fracture and to estimate the service load. In relation to a PL law that took effective on July 1, 1995, it is predicted that investigation into the cause of accidents will become an important social issue and it is thought that post-accidental analysis of the fracture surface will be important for investigating the cause of accidents.

Striations are commonly observed on fatigue-fractured surfaces and most of these correspond to the load cycle. The fact that crack growth rates $(\mathrm{da} / \mathrm{dN})$ correspond to striation spacing (s) is also well known.

Because the relationship between $\mathrm{da} / \mathrm{dN}, \mathrm{s}$, and $\Delta \mathrm{K}$ (stress intensity factors range $=$ $\mathrm{K}_{\max }-\mathrm{K}_{\min }$ ) or $\Delta \mathrm{K}_{\text {eff }}$ (effective stress intensity factors range $=\mathrm{K}_{\max }-\mathrm{K}_{\mathrm{op}}$ ), satisfies Paris' law, attempts have been made to estimate the service load from the striation spacing (s) on the fracture surface ${ }^{(1)-(3)}$.

However it is impossible to estimate maximum $\left(\mathrm{P}_{\max }\right)$ or minimum $\left(\mathrm{P}_{\min }\right)$ loads at the 
time of accident from the relationship between $\mathrm{da} / \mathrm{dN}, \mathrm{s}$, and $\Delta \mathrm{K}$. This is because even when $\Delta \mathrm{K}$ is constant, the $\mathrm{da} / \mathrm{dN}-\Delta \mathrm{K}$ relationship changes completely if $\mathrm{P}_{\max }$ and $\mathrm{P}_{\min }$ differ (that is, if the stress ratio $\mathrm{R}=\mathrm{P}_{\min } / \mathrm{P}_{\max }$ varies). Thus, most important thing is whether the stress ratio $\mathrm{R}$ can be determined from the configuration and dimensions of the striations. Until now, it has been difficult to estimate $\mathrm{R}$ during service load from the fracture surface; the author, however, using 2017-T4 aluminum alloy and type 304 stainless steel, have found that the difference in $\mathrm{R}$ is evident mainly in differences in striation configuration, particularly the differences in the ratio between height $(\mathrm{H})$ and width $(\mathrm{s})$.

As a result, it becomes clear that there is almost a one-to-one correspondence between $\mathrm{H} / \mathrm{s}$ (the striation height-width ratio) and stress ratio $\mathrm{R}$, and that the relationship between H/s and R for 2017-T4 aluminum alloy is the same as that of type 304 stainless steel . Even when stress ratio $\mathrm{R}$ remains constant, the $\mathrm{H} / \mathrm{s}$ values for many of the striations on the fracture surface are actually scattered over a wide range, necessitating statistical analysis of the measured $\mathrm{H} / \mathrm{s}$ data in order to accurately estimate $\mathrm{R}$.

For this reason it is important to measure the $\mathrm{H} / \mathrm{s}$ value for as many striations as possible, then investigate the trends of scattering. $\mathrm{H} / \mathrm{s}$ is usually measured by obliquely slicing a mountain of striation, but it is possible to obtain a valid $\mathrm{H} / \mathrm{s}$ only if the cutting planes are exceedingly sharp.

Therefore, the author have improved the method used in previous studies and developed a method that greatly increases the amount of valid measured data, thereby improving the reliability of service load estimates. This method, which will be discussed below, can be applied to the analysis of actual accidents.

Materials, Configuration of Specimen

The material used here was an 2017-T4 Al alloy. Table 1 shows its mechanical properties and Table 2 shows its chemical composition. Fig. 1 shows the configuration of a

Table 1. Mechanical properties of Al alloy.

\begin{tabular}{ccr}
\hline$\sigma_{0.2}$ & $\sigma_{\mathrm{B}}$ & $\Psi(\%)$ \\
\hline 270 & 435 & 23.8 \\
\hline
\end{tabular}

Table 2. Chemical composition of Al alloy.

\begin{tabular}{ccccc}
\hline $\mathrm{Al}$ & $\mathrm{Cu}$ & $\mathrm{Mg}$ & $\mathrm{Mn}$ & $\mathrm{Si}$ \\
\hline 94.9 & 3.7 & 0.6 & 0.4 & 0.4 \\
\hline
\end{tabular}

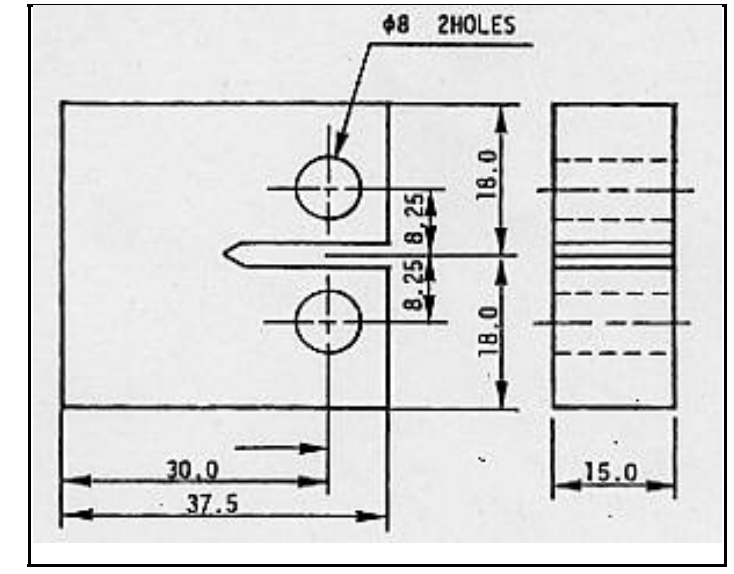

Fig. 1. Configuration of CT specimen. 
CT specimen. In the fatigue-crack growth tests, a servo-hydraulic testing system was used under various combinations of $\mathrm{R}$ and $\mathrm{P}_{\max }$. The fatigue fracture surfaces formed in this manner were observed by means of a scanning electron microscope (SEM), and striation width (s) and striation configuration (H/s) were measured by a laser microscope.

\section{Measuring Striation Configuration}

The observed striations are quite difficult to measure because the width is only 0.1 - $2 \mu \mathrm{m}$ and the height even smaller. Resolving this difficulty, therefore, becomes a key point.

As a highly accurate method for measuring the shape of a cross section of a striation, the author previously proposed a method for polishing after embedding specimens in plastic. This method, however, had the disadvantage that it dulls the edge of the polishing plane. The author then proposed a method of using a microtome to cut specimens embedded in plastic .

This method magnifies the striation, particularly the height, by cutting the striation at an angle. Thereby, this method enable us to measure the height of striation accurately. The quality of the cutting method affects the accuracy of the measurement. The drawback to this method is that relatively few valid measured values can be obtained, since the fracture surface of the specimen embedded in plastic might be damaged during the cutting process. Therefore, the author decided to test the method proposed here, wherein the problem is resolved by using a laser microscope method in which the specimen is not embedded in plastic ,but is measured directly by the laser microscope and 3-D equipment with SEM. This improved method is explained below.

When specimens are analyzed with the laser microscope, at first fracture surfaces of specimens are observed with a optical microscope and then a plateau on a fracture surface, which was horizontal to the optical axis, is selected as a measurement plane. Because if the measurement face inclined to optical axis, reflective efficiency of laser decreased and therefore the reliability of measurement data decreased.

Then 50 square $\mu \mathrm{m}$ of a horizontal fault plane on fracture surface was used as a measurement plane. These plane images were formed every $50 \mathrm{~nm}$ in perpendicular direction and a three dimensional image was formed by piling up twenty images as shown in Fig. 2. At last a perpendicular fault image was formed from this three dimensional image. Striation spacing (s) and height $(\mathrm{H})$ was measured with a definition shown in Fig. 3.

The measurement condition by 3-D equipment with SEM are indicated below.

Acceleration voltage is $20 \mathrm{kV}$, sample current is $1 \mathrm{nA}$ and the magnification on scanning area is $3000-10000$. As shown Fig. 4, 6 pieces of back scattered electron detectors are used in this measurement and each detector is fixed and height is calculated from data obtained by 6 pieces of back scattered electron detectors . 
Experimental results and observations

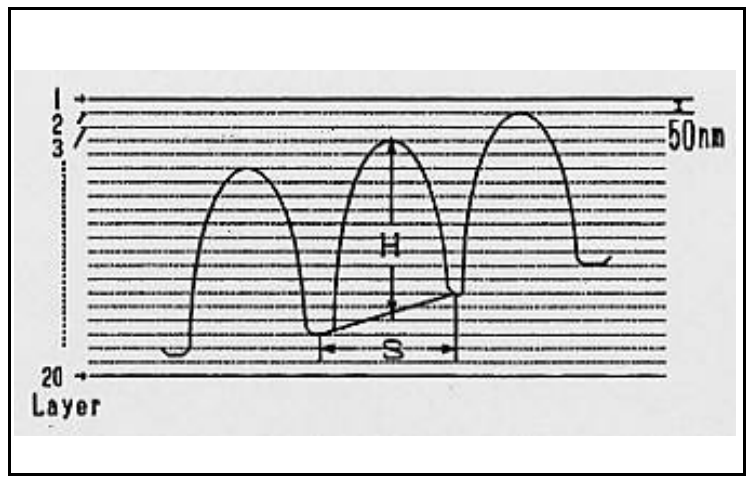

Fig. 2. Measuring method using a laser Microscope.
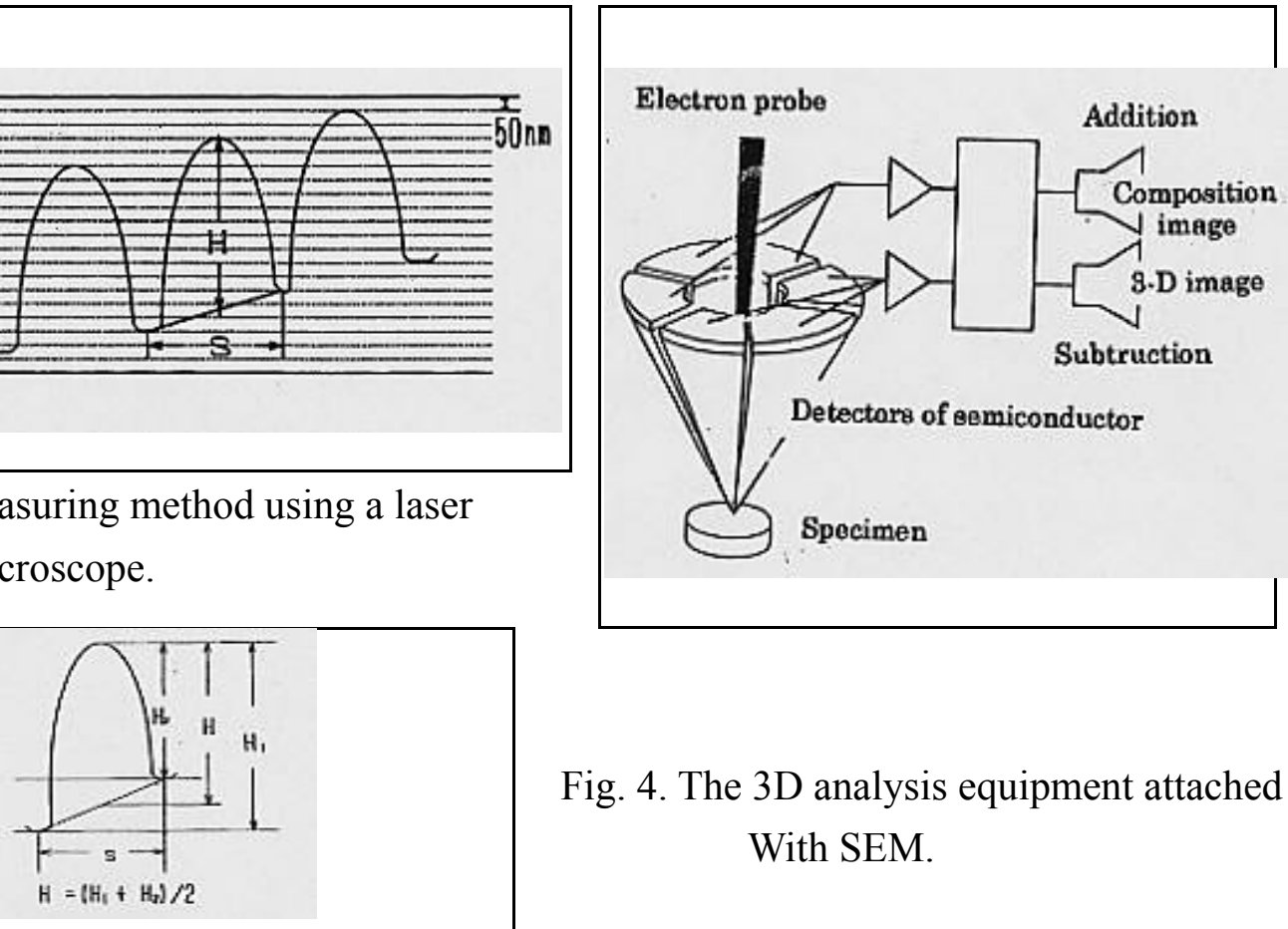

Fig. 4. The 3D analysis equipment attached With SEM.

Fig. 3 Definition of Striation width and height .

(1) The relationship between crack growth rate (da/dn and $\mathrm{s}$ ) and $\Delta \mathrm{K}$ under various values of stress ratio $\mathrm{R}$

The relationship between $\mathrm{da} / \mathrm{dN}$ measured by the replica method and $\Delta \mathrm{K}$ is shown in Fig. 5 and also that between striation spacing s measured by SEM and $\Delta \mathrm{K}$ in Fig. 6 . These figures indicate that crack growth rate is influenced not only by $\Delta \mathrm{K}$ but also by $\mathrm{R}$ and that there is no one-to-one correspondence between the crack growth rate and $\Delta \mathrm{K}$. Therefore,

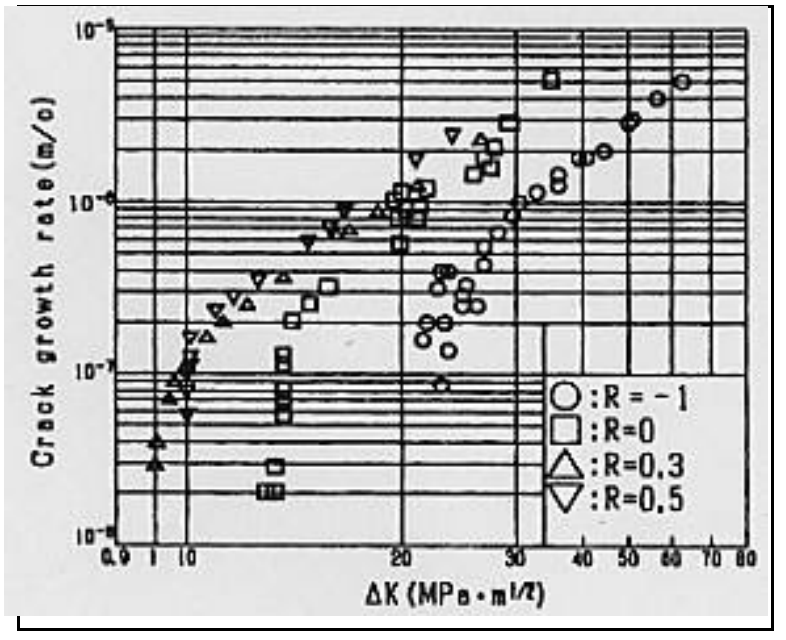

Fig. 5. Relationship between $\Delta \mathrm{K}$ and da/dN.

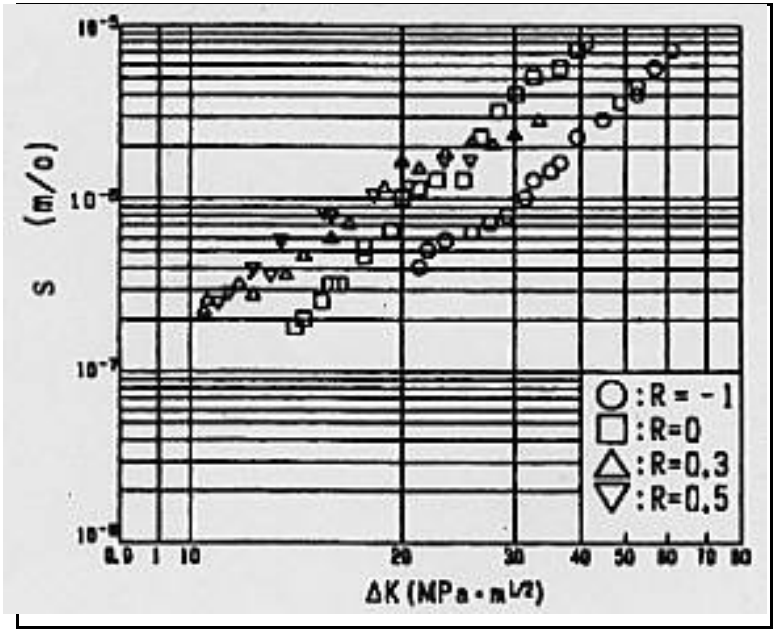

Fig. 6. Relationship between $\Delta \mathrm{K}$ and s. 
in order to determine service loading from fractured structures, not only crack growth rate ( $\mathrm{da} / \mathrm{dN}$ or $\mathrm{s}$ ) but also stress ratio $\mathrm{R}$ must be determined from the fracture surface.

(2) Influence of $\mathrm{R}$ on $\mathrm{H} / \mathrm{s}$

As a image of the laser microscope is shown Fig. 7, in the present study after assembling data from nearly 100 data in order to understand the overall tendencies, the distribution trends for those values were studied. As noted above, the results revealed a considerable range of distribution .

Furthermore, the average values of 100 data were compared. As it is equally true in the case of measuring with the laser microscope and 3-D equipment, the same method was adopted.

Fig. 8 shows the plotted data. Fig. 8 clearly shows that the values of H/s on each stress ratio $\mathrm{R}$ obtained by microtome method are nearly as same as those obtained by the methods using the laser microscope and 3-D equipment. Therefore, it was found that stress ratio $\mathrm{R}$ could be measured from fracture surface by the methods of measuring striation figure with laser microscope and 3-D equipment. By both methods, striation can be easily searched because striation can be observed by optical microscope and SEM respectively.

Thus, as the height of striation is measured directly by using laser microscope and 3-D equipment with SEM, striation figure became able to be measured with ease and simplicity.

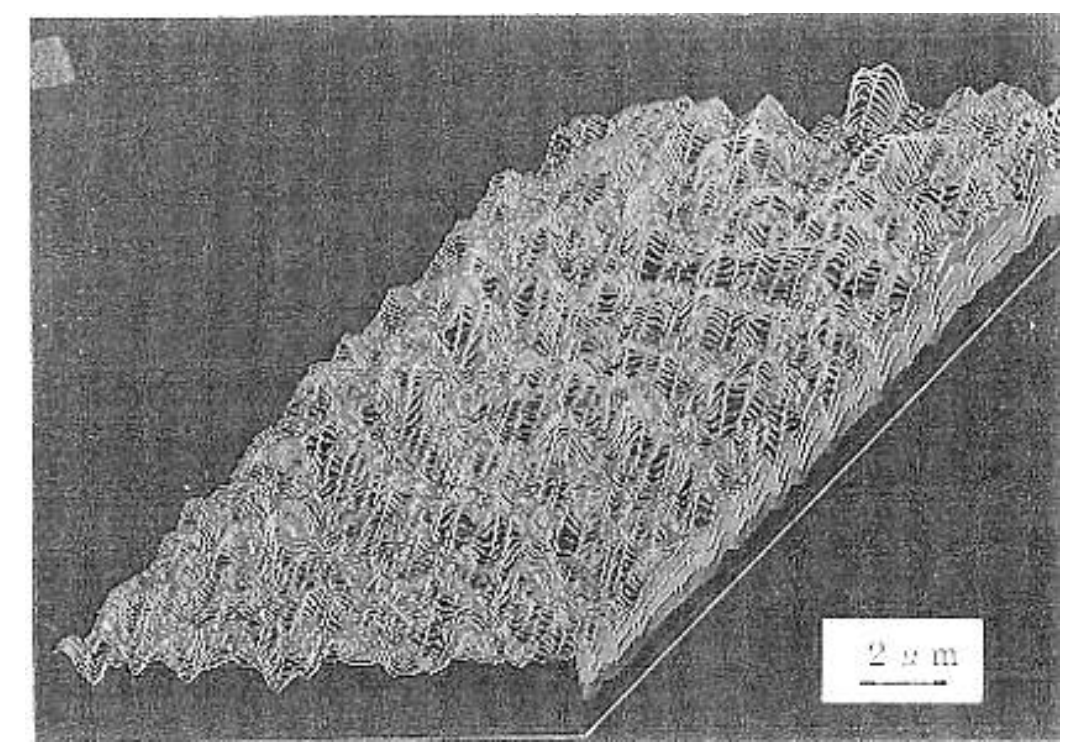

Fig. 7. A image of the laser microscope.

Conclusion

In this investigation the figure of striation were measured with laser microscope and 


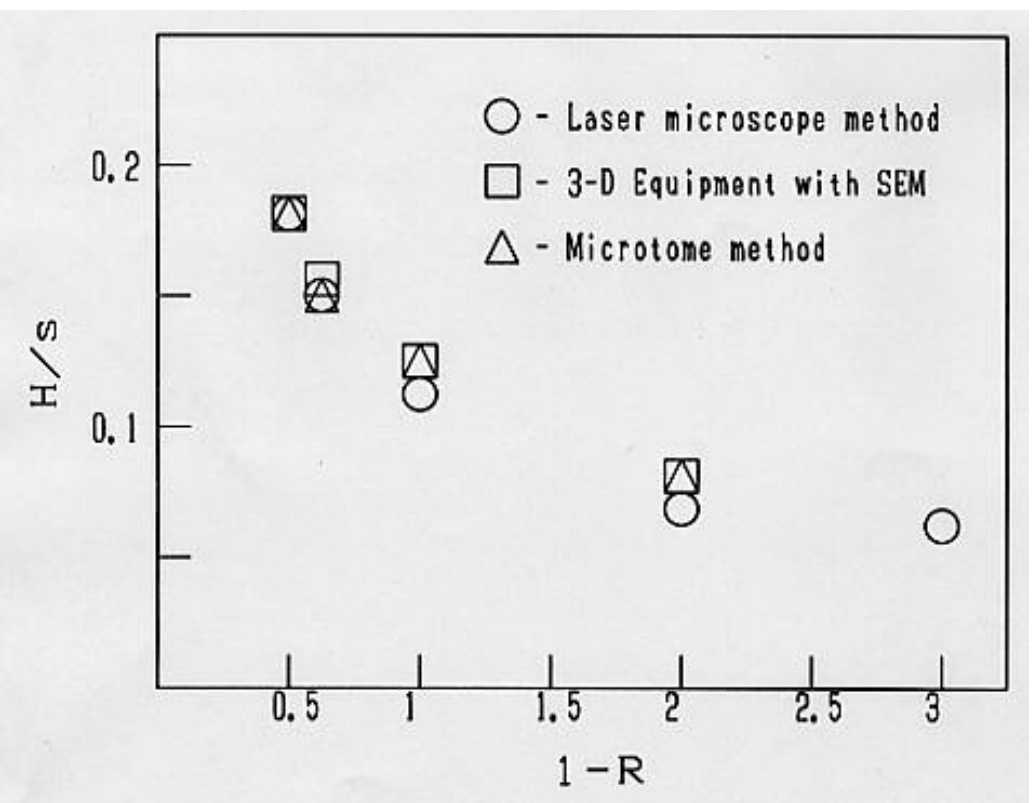

Fig. 8. The relationship between $\mathrm{H} / \mathrm{s}$ and $\mathrm{R}$.

3-D equipment with SEM. Striation can be easily searched with a microscope and SEM. Therefore, the figure can be easily measured with laser microscope and 3-D equipment. In this report the new methods, which are that the figure of striation are directly measured with laser microscope and 3-D equipment, were developed. Therefore, this new methods led us to measure the figure of striations more accurately and easily.

The results obtained through the present investigation are as follows.

(1) The methods that the figure of striations are directly measured with laser microscope and 3-D equipment without making section with a microtome are developed. By both methods, the figure of striations at every point can be easily measured.

(2) Determining the stress ratio $\mathrm{R}$ from the average values of 100 data can be recommended as a practical and valid method. The correlation between $\mathrm{H} / \mathrm{s}$ and $\mathrm{R}$ measured with laser microscope and 3-D equipment are the same as that with measured by sectioning.

Therefore, it was found that the stress ratio $\mathrm{R}$ can be estimated with accurate and ease by the method with laser microscope and 3-D equipment.

\section{REFERENCES}

(1) Trans. Jap. Soc. Mater. Engng. Sci. Fract. Meeting., J. Jap. Soc. Mech. Engng. 76, 1973, pp.1203-1208 (in Japanese).

(2) R. Koterazawa, Lecture Fractography (5), J. Soi. Mater. Sci. 23, 1974, pp.803-813 (in Japanese).

(3) K. Furukawa, Y. Murakami, A Method for Predicting Service Load from the Width and Height of Striation. J. Soc. Mater. Sci. Vol.45, 1996, 340-345 (in Japanese). 